Article

\title{
Simplified Minimum Copper Loss Remedial Control of a Five-Phase Fault-Tolerant Permanent-Magnet Vernier Machine under Short-Circuit Fault
}

\author{
Chenyu Gu, Wenxiang Zhao * and Bufeng Zhang \\ School of Electrical and Information Engineering, Jiangsu University, Zhenjiang 212013, China; \\ chenyuGu92@163.com (C.G); zhangbufeng1990@163.com (B.Z.) \\ * Correspondence: zwx@ujs.edu.cn; Tel.: +86-511-8879-1960
}

Academic Editor: Paolo Mercorelli

Received: 9 July 2016; Accepted: 13 October 2016; Published: 25 October 2016

\begin{abstract}
A fault-tolerant permanent-magnet vernier (FT-PMV) machine incorporates the merits of high fault-tolerant capability and high torque density. In this paper, a new remedial control is proposed for a five-phase FT-PMV machine with short-circuit fault of stator windings. Based on the principle of copper loss minimization, the aims of the proposed control strategy are to keep magnetic motive force (MMF) unchanged and minimize torque ripple. The proposed remedial control strategy contains two parts. Firstly, the remedial currents of the healthy phases are used to compensate for the ripple of MMF caused by the short-circuit current. Secondly, an open-circuit fault-tolerant control strategy is used to compensate for the lack of normal torque in the fault phase. Finally, the vector sum of two parts is adopted to derive the remedial currents. The final expression of the proposed remedial current is simpler than that than these previous methods. In addition, the proposed remedial currents are sinusoidal, which can reduce the reactive component in instantaneous power produced by pulsating torque and iron loss of a sine back-EMF machine. A FT-PMV prototype is built. The simulations and the experiments verify the effectiveness of the proposed strategy.
\end{abstract}

Keywords: remedial control; fault-tolerant permanent-magnet vernier (FT-PMV) machine; short-circuit fault; torque

\section{Introduction}

For some high reliability applications such as aerospace and electric vehicle, continued operation of the drive is essential [1-3]. Using electric vehicles as an example, such capability is related to the ability to continue operation at a modest speed to finish the trip or at least reach a repair shop. In much of the literature, the fault-tolerant operations of conventional three-phase machines under open-circuit fault condition have been reported [4-7]. Compared with traditional three-phase drives, multiphase machine drives have a number of advantages, such as low harmonic currents, smooth torque ripple and high torque capability [8]. Multiphase machines can keep operating with the remaining healthy phases when open-circuit fault occurs in one or two phases. In addition, multiphase machines can operate without additional hardware under faulty conditions [9-12].

On the other hand, fault-tolerant permanent-magnet (PM) machines have attracted much interest in recent years [13-16], but they suffer from the compromise between fault-tolerant capability and torque density. In [17], a five-phase fault-tolerant PM vernier (FT-PMV) machine with improved torque capability was proposed. Also, though many works seek optimal fault-tolerant control strategies, most of them focus on open-circuit fault, rather than short-circuit fault. An optimal control technique for a multiphase PM machine under various open-circuit faults was presented in [18], in which the copper loss and the torque ripple were considered. The proposed fault-tolerant control methods in [19] 
considered the fundamental and third-harmonic current components together for the excitation of the healthy stator phases. In [20], a mathematical analysis based on the space vector representation of a multiphase system was discussed and assessed under open-circuit fault. In order to generate optimal current references in fault mode, a vector approach was reported in [21], which requires relatively simple computations. The authors of [22] adopted a new control strategy for fault-tolerant operation of the redundant flux-switching PM machine drive by injecting the harmonic currents, in which the capability limitation of the power converter is considered. A generalized optimal fault-tolerant control technique was proposed in $[23,24]$ for a five-phase PM machine drives with open-circuit fault. Few works focus on continued operation of multiphase PM machines under short-circuit fault conditions [25-30]. In [31], a remedial operation was investigated by using the open-end winding drive topology.

In this paper, an offline closed-form solution for short-circuit fault will be proposed, discussed and verified. It should be noted that the existing offline closed form fault-tolerant solutions were usually used for open-circuit fault, rather than for short-circuit fault. This proposed control strategy bases on the copper loss minimization theory and aims to keep magnetic motive force (MMF) unchanged, thus obtaining smooth output torque. The short-circuit fault in one phase can be divided into two parts. Namely, one is caused by the short-circuit current, while the other is due to the lack of normal torque, which can be considered the open-circuit fault condition. As opposed from the existing strategies of multiphase PM machines under short-circuit fault conditions, the proposed strategy is simply divided into two steps. Firstly, currents in healthy phases are used to compensate for the ripple of MMF caused by the short-circuit current. Secondly, the open-circuit fault-tolerant control strategy is used to compensate for the lack of the normal torque in the faulty phase. Finally, a new remedial current can be calculated by utilizing the vector sum of two parts of the strategy.

In Section 2, the FT-PMV machine will be briefly presented. In Section 3, the remedial current control strategy under open-circuit fault condition will be given. The remedial short-circuit current control strategy will be derived in Section 4. Moreover, in Section 5, the finite-element analysis (FEA) and the experimental results will be used to verify the proposed strategy. In Section 6, comparisons between and discussions about the proposed method and these existing methods will be presented. Finally, conclusions will be drawn in Section 7.

\section{Topology and Feature}

A five-phase FT-PMV machine is shown in Figure 1. The number of stator slots is 20 and the rotor has 31 pole pairs. This machine has each coil wound around a single tooth, which is the so-called single-layer fractional-slot concentrated winding. For conventional direct-drive machine topologies with increased number of poles, slots and windings, magnetic circuits are usually required to generate high torque. Such a machine inevitably increases the machine volume and weight. FT-PMV machines with concentrated windings can offer high torque capability while reducing the number of slots and copper loss. FT-PMV machines can effectively modulate the high-speed rotating field of the armature windings and the low-speed rotating field of the PM outer rotor by adopting flux-modulation poles (FMPs). Hence, the armature poles number should differ from the rotor poles one, which breaks the traditional design rule of PM machines. Also, the volume of the stator with vernier structure will not increase with the large number of PM poles.

Moreover, the predicted FEA-based back electromotive force (back-EMF) of the five-phase FT-PMV machine is shown in Figure 2. Due to the insulation problem, the windings terminal of one phase is short-circuited. Then, its FEA-based short-circuit current is shown in Figure 3. It can be seen that the short-circuit current is limited because fault-tolerant design is adopted [17]. The main design data are given in Table 1. 


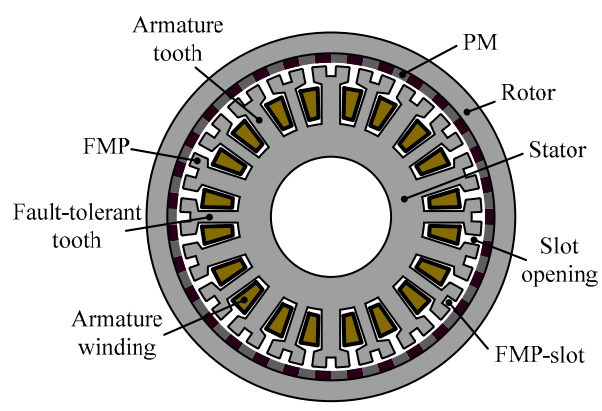

Figure 1. Fault-tolerant permanent-magnet vernier (FT-PMV) machine.

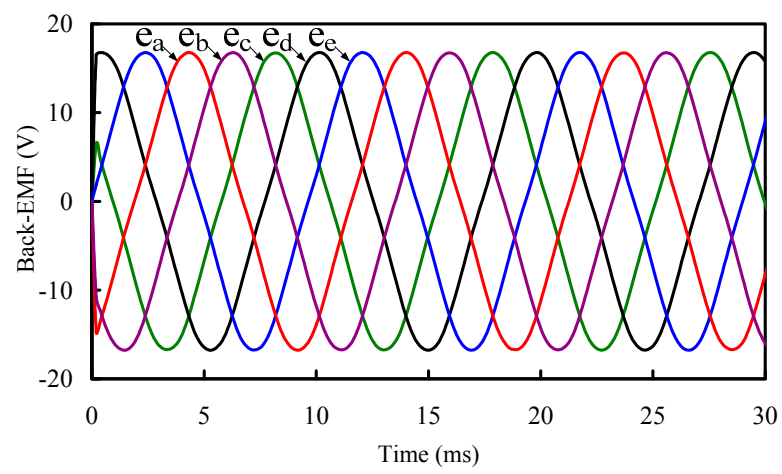

Figure 2. Back-EMF.

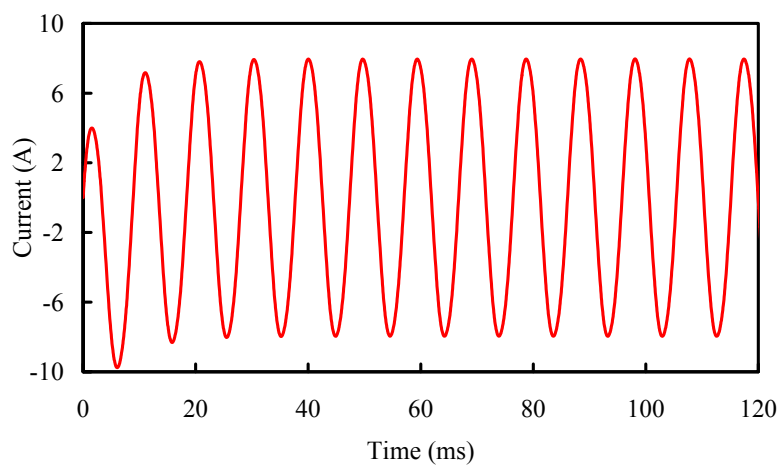

Figure 3. Short-circuit current.

Table 1. Motor parameters.

\begin{tabular}{cc}
\hline Rated output power (kW) & 1.8 \\
Rated current (A) & 10 \\
Rated speed (rpm) & 200 \\
Number of phases & 5 \\
Number of stator slots & 20 \\
Number of rotor pole pairs & 31 \\
Number of FMPs & 40 \\
Rated voltage (V) & 70 \\
Current density (A/mm $\mathbf{2}^{\text {) }}$ & 6.6 \\
Outside stator radius (mm) & 60 \\
Outside rotor radius (mm) & 70 \\
Stack length (mm) & 60 \\
Air-gap length (mm) & 0.5 \\
PM thickness (mm) & 3.2 \\
Fault-tolerant tooth length (mm) & 1.9 \\
Armature tooth length (mm) & 3.3 \\
Number of stator turns per coil & 48 \\
\hline
\end{tabular}


The proposed remedial control strategy divides the short-circuit problem into two parts to simplify the remedial problem. One part is the compensation of the open-circuit fault which is used to achieve the required torque. The other part is the compensation of the short-circuit fault which is used to eliminate pulsating torque.

\section{Open-Circuit Fault-Tolerant Control}

The back-EMFs of the five-phase FT-PMV machine can be described as

$$
\left\{\begin{array}{l}
e_{a}=E \cos (\omega t) \\
e_{b}=E \cos \left(\omega t-\frac{2 \pi}{5}\right) \\
e_{c}=E \cos \left(\omega t-\frac{4 \pi}{5}\right) \\
e_{d}=E \cos \left(\omega t+\frac{4 \pi}{5}\right) \\
e_{e}=E \cos \left(\omega t+\frac{2 \pi}{5}\right)
\end{array}\right.
$$

where $E$ is the amplitude of the back-EMF, and $\omega$ is the electrical angular velocity. Due to its sinusoidal back-EMF, this FT-PMV machine is suitable for brushless ac (BLAC) operation. Hence, the currents can be expressed as

$$
\left\{\begin{array}{l}
i_{a}=I \cos (\omega t) \\
i_{b}=I \cos \left(\omega t-\frac{2 \pi}{5}\right) \\
i_{c}=I \cos \left(\omega t-\frac{4 \pi}{5}\right) \\
i_{d}=I \cos \left(\omega t+\frac{4 \pi}{5}\right) \\
i_{e}=I \cos \left(\omega t+\frac{2 \pi}{5}\right)
\end{array}\right.
$$

where $I$ is the amplitude of the phase currents. According to (1) and (2), the stator phases MMF can be written as

$$
\left\{\begin{array}{l}
M M F_{a}(\varphi, \omega t)=N I \cos \varphi \cos (\omega t) \\
M M F_{b}(\varphi, \omega t)=N I \cos \left(\varphi-\frac{2 \pi}{5}\right) \cos \left(\omega t-\frac{2 \pi}{5}\right) \\
M M F_{c}(\varphi, \omega t)=N I \cos \left(\varphi-\frac{4 \pi}{5}\right) \cos \left(\omega t-\frac{4 \pi}{5}\right) \\
M M F_{d}(\varphi, \omega t)=N I \cos \left(\varphi+\frac{4 \pi}{5}\right) \cos \left(\omega t+\frac{4 \pi}{5}\right) \\
M M F_{e}(\varphi, \omega t)=N I \cos \left(\varphi+\frac{2 \pi}{5}\right) \cos \left(\omega t+\frac{2 \pi}{5}\right)
\end{array}\right.
$$

where $N$ is the total number of turn per phase and $\varphi$ is the spatial angle. Hence, the sum of MMF of all phases can be given as

$$
M M F_{1}(\varphi, \omega t)=M M F_{a}(\varphi, \omega t)+M M F_{b}(\varphi, \omega t)+M M F_{c}(\varphi, \omega t)+M M F_{d}(\varphi, \omega t)+M M F_{e}(\varphi, \omega t)
$$

After calculation, it can be written as

$$
M M F_{1}(\varphi, \omega t)=\frac{5}{4} N I\left(\mathrm{e}^{\mathrm{j} \omega t} \mathrm{e}^{-\mathrm{j} \varphi}+\mathrm{e}^{-\mathrm{j} \omega t} \mathrm{e}^{\mathrm{j} \varphi}\right)
$$

Moreover, $M M F_{1}$ can also be expressed as

$$
M M F_{1}=\left\{N\left[\left(i_{a}+\mathrm{e}^{-\mathrm{j} \frac{2 \pi}{5}} i_{b}+\mathrm{e}^{-\mathrm{j} \frac{4 \pi}{5}} i_{c}+\mathrm{e}^{\mathrm{j} \frac{4 \pi}{5}} i_{d}+\mathrm{e}^{\mathrm{j} \frac{2 \pi}{5}} i_{e}\right) \mathrm{e}^{\mathrm{j} \varphi}+\left(i_{a}+\mathrm{e}^{\mathrm{j} \frac{2 \pi}{5}} i_{b}+\mathrm{e}^{\mathrm{j} \frac{4 \pi}{5}} i_{c}+\mathrm{e}^{-\mathrm{j} \frac{4 \pi}{5}} i_{d}+\mathrm{e}^{-\mathrm{j} \frac{2 \pi}{5}} i_{e}\right) \mathrm{e}^{-\mathrm{j} \varphi}\right]\right\}
$$

Equation (7) can be obtained on the basis of (5) and (6).

$$
\frac{5}{2} I \mathrm{e}^{\mathrm{j} \omega t}=i_{a}+\mathrm{e}^{\mathrm{j} \frac{2 \pi}{5}} i_{b}+\mathrm{e}^{\mathrm{j} \frac{4 \pi}{5}} i_{c}+\mathrm{e}^{-\mathrm{j} \frac{4 \pi}{5}} i_{d}+\mathrm{e}^{-\mathrm{j} \frac{2 \pi}{5}} i_{e}
$$

Here, the open-circuit fault of phase-a is chosen as an example. MMF can be kept unchanged when $i_{a}$ is equal to zero in (7). Equation (7) can be written as

$$
\frac{5}{2} I \mathrm{e}^{\mathrm{j} \omega t}=\mathrm{e}^{\mathrm{j} \frac{2 \pi}{5}} i_{b}^{\prime}+\mathrm{e}^{\mathrm{j} \frac{4 \pi}{5}} i_{c}^{\prime}+\mathrm{e}^{-\mathrm{j} \frac{4 \pi}{5}} i_{d}^{\prime}+\mathrm{e}^{-\mathrm{j} \frac{2 \pi}{5}} i_{e}^{\prime}
$$


It can be assumed that

$$
\left\{\begin{array}{l}
i_{b}^{\prime}=I\left[x_{2} \cos (\omega t)+y_{2} \sin (\omega t)\right] \\
i_{c}^{\prime}=I\left[x_{3} \cos (\omega t)+y_{3} \sin (\omega t)\right] \\
i_{d}^{\prime}=I\left[x_{4} \cos (\omega t)+y_{4} \sin (\omega t)\right] \\
i_{e}^{\prime}=I\left[x_{5} \cos (\omega t)+y_{5} \sin (\omega t)\right]
\end{array}\right.
$$

According to (8) and (9), it can be obtained as

$$
\left\{\begin{array}{l}
0.309 x_{2}-0.809 x_{3}-0.809 x_{4}+0.309 x_{5}=\frac{5}{2} \\
0.309 y_{2}-0.809 y_{3}-0.809 y_{4}+0.309 y_{5}=0 \\
0.951 x_{2}+0.588 x_{3}-0.588 x_{4}-0.951 x_{5}=0 \\
0.951 y_{2}+0.588 y_{3}-0.588 y_{4}-0.951 y_{5}=\frac{5}{2}
\end{array}\right.
$$

An additional reasonable constraint is as follows:

$$
i_{b}^{\prime}+i_{c}^{\prime}+i_{d}^{\prime}+i_{e}^{\prime}=0
$$

According to (11), it can be written as

$$
\left\{\begin{array}{l}
x_{2}+x_{3}+x_{4}+x_{5}=0 \\
y_{2}+y_{3}+y_{4}+y_{5}=0
\end{array}\right.
$$

According to (10) and (12), the results of $x_{2}, y_{2}, x_{3}, y_{3}, x_{4}, y_{4}, x_{5}$ and $y_{5}$ are not unique, so it is necessary to add a target function to make the final result unique. Then, the target function $F$ aims to minimize copper loss can be given as [32]

$$
F\left(x_{2}, y_{2}, x_{3}, y_{3}, x_{4}, y_{4}, x_{5}, y_{5}\right)=\left(x_{2}^{2}+y_{2}{ }^{2}\right)+\left(x_{3}{ }^{2}+y_{3}{ }^{2}\right)+\left(x_{4}{ }^{2}+y_{4}{ }^{2}\right)+\left(x_{5}{ }^{2}+y_{5}{ }^{2}\right)
$$

Among all the results, there will be some results of minimizing $F$, which can be called the optimal results. According to (10), (12) and (13), a built-in function of MATLAB based on SQP algorithm can be used to achieve the optimal results of $x_{2}, y_{2}, x_{3}, y_{3}, x_{4}, y_{4}, x_{5}$ and $y_{5}$.

$$
\left\{\begin{array}{l}
i_{b}^{\prime}=I[1.118 \cos \omega t+0.951 \sin \omega t] \\
i_{c}^{\prime}=I[-1.118 \cos \omega t+0.588 \sin \omega t] \\
i_{d}^{\prime}=I[-1.118 \cos \omega t-0.588 \sin \omega t] \\
i_{e}^{\prime}=I[1.118 \cos \omega t-0.951 \sin \omega t]
\end{array}\right.
$$

Also, it can be given as

$$
\left\{\begin{array}{l}
i_{b}^{\prime}=1.4678 I \cos (\omega t-0.2244 \pi) \\
i_{c}^{\prime}=1.2631 I \cos (\omega t-0.8459 \pi) \\
i_{d}^{\prime}=1.2631 I \cos (\omega t+0.8459 \pi) \\
i_{e}^{\prime}=1.4678 I \cos (\omega t+0.2244 \pi)
\end{array}\right.
$$

In this case, when open-circuit fault happens in one phase of stator windings, the currents in remaining healthy phases can be used to keep $M M F_{1}$ unchanged based on the principle of copper loss minimization.

\section{Short-Circuit Fault-Tolerant Control}

A fault-tolerant current control strategy for the five-phase FT-PMV machine under short-circuit condition will be discussed in this section. Compared with that under open-circuit fault condition, the torque ripple of the FT-PMV machine under short-circuit fault condition includes two parts. One is caused by the short-circuit current, while the other owes to the lack of the normal torque which can be considered as the open-circuit fault condition. Corresponding to short-circuit fault, the proposed 
remedial control strategy also has two aspects. First of all, the currents in healthy phases are used to compensate for the ripple of MMF caused by the short-circuit current. MMF can be kept at zero, so the torque pulsation can be eliminated. Then, open-circuit fault-tolerant control strategy is used to compensate for the lack of the normal torque. Finally, a new remedial control strategy can be derived by utilizing the vector sum of both fault-tolerant control strategies.

When phase-a is with short-circuit fault in stator windings, its short-circuit current can be written as

$$
i_{a f}=I_{f} \sin (\omega t-\theta)
$$

where $I_{f}$ is the amplitude of the short-circuit current, and $\theta$ is the angle between short-circuit current and back-EMF in faulty phase. The vector sum of the MMF can be written as

$$
M M F_{2}=N i_{a f}+a N i_{b}^{\prime \prime}+a^{2} N i_{c}^{\prime \prime}+a^{3} N i_{d}^{\prime \prime}+a^{4} N i_{e}^{\prime \prime}
$$

where $i_{a f}$ is the short-circuit current in phase-a. The healthy currents aim to compensate the torque ripple caused by the short-circuit current and a is $\mathrm{e}^{(2 / 5 \pi) \mathrm{j}}$.

$M M F_{2}$ in (17) is kept to zero, so the total MMF of the FT-PMV machine is the sum of $M M F_{1}$ and $M M F_{2}$, which can be kept constant. Based on (16) and (17), (18) can be obtained as

$$
\left\{\begin{array}{l}
0.309 i_{b}^{\prime \prime}-0.809 i_{c}^{\prime \prime}-0.809 i_{d}^{\prime \prime}+0.309 i_{e}^{\prime \prime}+i_{a f}=0 \\
0.951 i_{b}^{\prime \prime}+0.588 i_{c}^{\prime \prime}+0.588 i_{d}^{\prime \prime}+0.951 i_{e}^{\prime \prime}=0
\end{array}\right.
$$

In (18), there are infinite results for the compensating currents without conditional constraints. In order to compensate for the ripple caused by the short-circuit current in phase-a, the healthy currents can be calculated. It can be assumed that

$$
\left\{\begin{array}{l}
i_{b}^{\prime \prime}=x_{b} \cos (\omega t)+y_{b} \sin (\omega t) \\
i_{c}^{\prime \prime}=x_{c} \cos (\omega t)+y_{c} \sin (\omega t) \\
i_{d}^{\prime \prime}=x_{d} \cos (\omega t)+y_{d} \sin (\omega t) \\
i_{e}^{\prime \prime}=x_{e} \cos (\omega t)+y_{e} \sin (\omega t)
\end{array}\right.
$$

where $x_{b}, y_{b}, x_{c}, y_{c}, x_{d}, y_{d}, x_{e}$ and $y_{e}$ are unknown quantities. The proposed control strategy aims to minimize the copper loss. So, the target function $f$ can be given as

$$
f\left(x_{b}, y_{b}, x_{c}, y_{c}, x_{d}, y_{d}, x_{e}, y_{e}\right)=\left(x_{b}^{2}+y_{b}^{2}\right)+\left(x_{c}^{2}+y_{c}^{2}\right)+\left(x_{d}^{2}+y_{d}^{2}\right)+\left(x_{e}^{2}+y_{e}^{2}\right)
$$

According to (18) and (19), (21) can be obtained as

$$
\left\{\begin{array}{l}
0.309 x_{b}-0.809 x_{c}-0.809 x_{d}+0.309 x_{e}=-I_{f} \sin \theta \\
0.309 y_{b}-0.809 y_{c}-0.809 y_{d}+0.309 y_{e}=I_{f} \cos \theta \\
0.951 x_{b}+0.588 x_{c}-0.588 x_{d}-0.951 x_{e}=0 \\
0.951 y_{b}+0.588 y_{c}-0.588 y_{d}-0.951 y_{e}=0
\end{array}\right.
$$

According to (21), the results of $x_{b}, y_{b}, x_{c}, y_{c}, x_{d}, y_{d}, x_{e}$ and $y_{e}$ are not unique, so it is necessary to use a target function to make the final result unique. Many results can minimize the result of (20) among all the results and they can be called the optimal results.

The compensation, which owes to the lack of the normal torque, can be considered as the open-circuit fault condition. The strategy has been discussed in Section 3 and described in (15). Based on (15) and (19), the final current control strategy for short-circuit fault can be given as

$$
\left\{\begin{array}{l}
i_{b}^{*}=i_{b}^{\prime \prime}+i_{b}^{\prime} \\
i_{c}^{*}=i_{c}^{\prime \prime}+i_{c}^{\prime} \\
i_{d}^{*}=i_{d}^{\prime \prime}+i_{d}^{\prime} \\
i_{e}^{*}=i_{e}^{\prime \prime}+i_{e}^{\prime}
\end{array}\right.
$$


The universal current control strategy can also be written as

$$
\left\{\begin{array}{l}
i_{b}^{*}=x_{b} \cos (\omega t)+y_{b} \sin (\omega t)+1.4678 I \sin (\omega t-0.2244 \pi) \\
i_{c}^{*}=x_{c} \cos (\omega t)+y_{c} \sin (\omega t)+1.2631 I \sin (\omega t-0.8459 \pi) \\
i_{d}^{*}=x_{d} \cos (\omega t)+y_{d} \sin (\omega t)+1.2631 I \sin (\omega t+0.8459 \pi) \\
i_{e}^{*}=x_{e} \cos (\omega t)+y_{e} \sin (\omega t)+1.4678 I \sin (\omega t+0.2244 \pi)
\end{array}\right.
$$

When the windings terminal of one phase is with short-circuit fault, other phases can continue to operate. The rotor speed of $200 \mathrm{rpm}$ will be discussed as example. The short-circuit current is presented in Figure 3. Based on the back-EMF and the short-circuit current, $I_{f}$ and $\theta$ in (16) can be obtained. Then, $x_{b}, y_{b}, x_{c}, y_{c}, x_{d}, y_{d}, x_{e}$ and $y_{e}$ in (21) can be calculated based on (20) and (21). $I_{f}$ and $\theta$ will change for different machines and different operating conditions, and then $x_{b}, y_{b}, x_{c}, y_{c}, x_{d}, y_{d}, x_{e}$ and $y_{e}$ can be calculated. Based on the FEA results, $I_{f}$ and $\theta$ can be obtained as follows

$$
\left\{\begin{array}{l}
I_{f}=8.04 A \\
\theta=1.42 \pi
\end{array}\right.
$$

According to (20), (21) and (24), a built-in function of MATLAB based on SQP algorithm can be used to achieve the optimal results of $x_{b}, y_{b}, x_{c}, y_{c}, x_{d}, y_{d}, x_{e}$ and $y_{e}$. Then, the currents compensating for the ripple of MMF caused by the short-circuit current are given as

$$
\left\{\begin{array}{l}
i_{b}^{\prime \prime}=-1.60 \cos (\omega t)+0.43 \sin (\omega t) \\
i_{c}^{\prime \prime}=4.19 \cos (\omega t)-1.12 \sin (\omega t) \\
i_{d}^{\prime \prime}=4.19 \cos (\omega t)-1.12 \sin (\omega t) \\
i_{e}^{\prime \prime}=-1.60 \cos (\omega t)+0.43 \sin (\omega t)
\end{array}\right.
$$

The final remedial currents of the short-circuit current control strategy can be given as

$$
\left\{\begin{array}{l}
i_{b}^{*}=-1.60 \cos (\omega t)+0.43 \sin (\omega t)+1.4678 I \sin (\omega t-0.2244 \pi) \\
i_{c}^{*}=4.19 \cos (\omega t)-1.12 \sin (\omega t)+1.2631 I \sin (\omega t-0.8459 \pi) \\
i_{d}^{*}=4.19 \cos (\omega t)-1.12 \sin (\omega t)+1.2631 I \sin (\omega t+0.8459 \pi) \\
i_{e}^{*}=-1.60 \cos (\omega t)+0.43 \sin (\omega t)+1.4678 I \sin (\omega t+0.2244 \pi)
\end{array}\right.
$$

\section{Validation}

\subsection{Simulation}

First, Figure 4 shows the FEA-based currents and output torque waveforms of the normal five-phase FT-PMV machine. It can be seen that the current waveforms are sinusoidal and the corresponding average torque and torque ripple factor of the machine drive are $3.6 \mathrm{Nm}$ and $24.5 \%$, respectively. In [33], the back-EMF harmonics, which interact with the sinusoidal phase current waveforms to generate torque ripple for a five-phase machine, are 9th, 11th, 19th, 21st, etc. Hence, the output torque ripple mainly results from the cogging torque.

Second, the fault currents and torque under short-circuit fault condition are shown in Figure 5. It can be seen from Figure $5 b$ that the torque has high pulsation under fault conditions.

Third, the fault-tolerant performance with the current control strategy in (26) is shown in Figure 6 under single-phase short-circuit fault. The fault-tolerant currents are presented in Figure 6a. The corresponding average torque and torque ripple factor of the machine drive are $3.5 \mathrm{Nm}$ and $37.0 \%$, respectively. By comparing the torque performances at normal and remedial operations, it can be found that torque ripple is minimized and the torque performance is maintained when the strategy is adopted. Since the low-order harmonics in (23) are neglected, the FT-PMV machine at fault-tolerant operation has relatively significant torque ripple. 


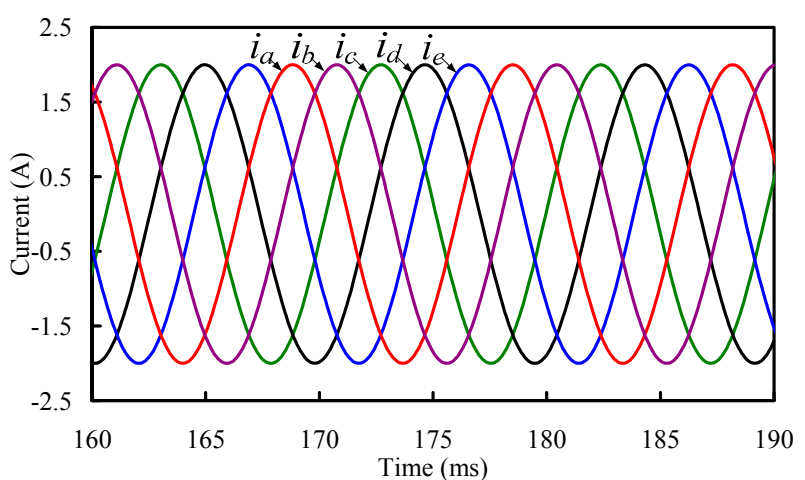

(a)

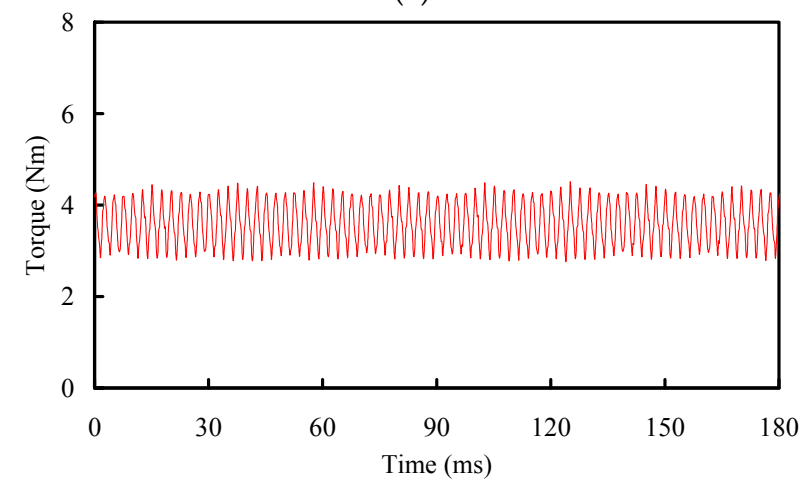

(b)

Figure 4. Performance under healthy condition: (a) Currents; (b) Output torque.

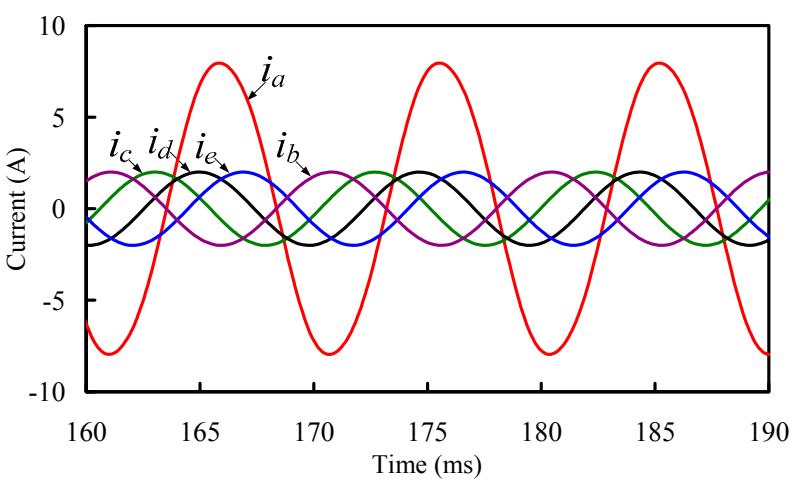

(a)

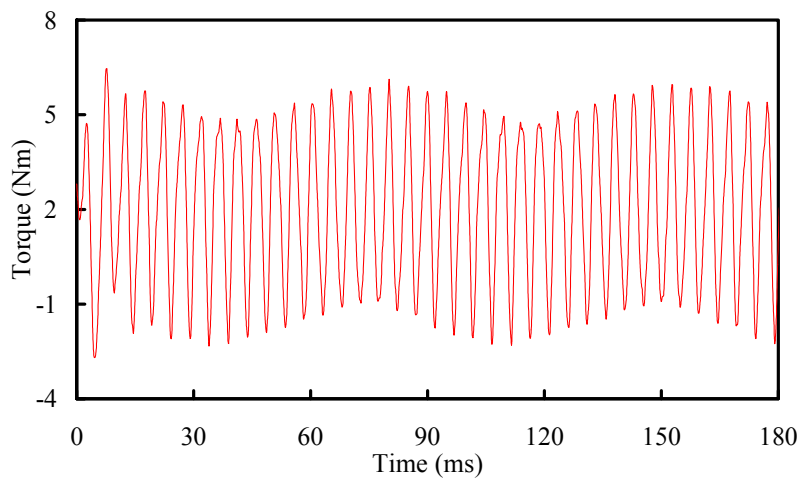

(b)

Figure 5. Performance under short-circuit fault condition: (a) Currents; (b) Output torque. 


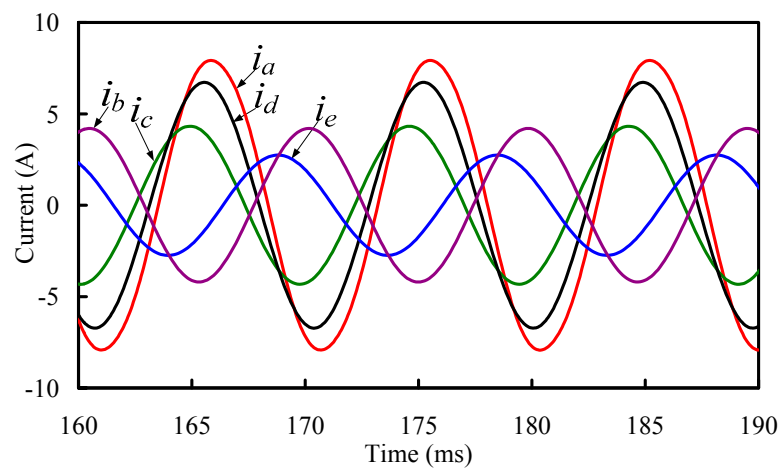

(a)

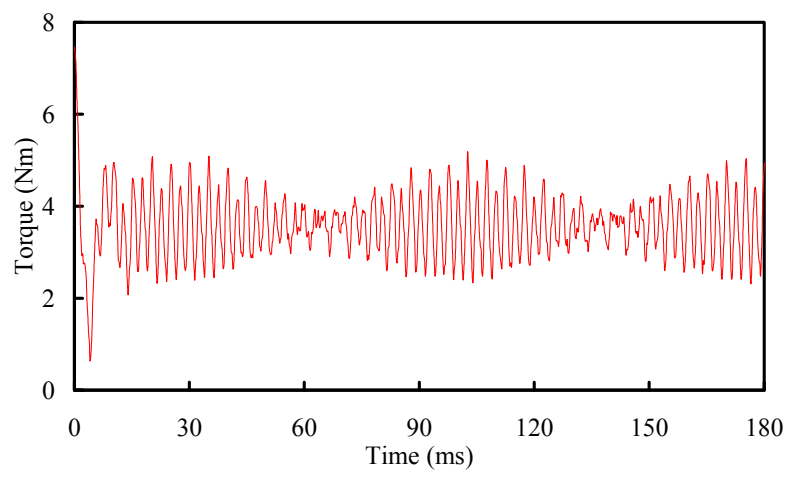

(b)

Figure 6. Performance under fault-tolerant condition: (a) Currents; (b) Output torque.

In addition, output torque and torque ripple for the five-phase FT-PMV machine under healthy, fault and fault-tolerant conditions are compared in Table 2. It can be concluded that torque ripple under fault-tolerant operation can be minimized with the proposed strategy. Table 3 compares the compositions of harmonics for the proposed method and those presented methods in [28,29].

Table 2. Torque performance under various conditions.

\begin{tabular}{cccc}
\hline Torque & Normal & Fault & Remedial \\
\hline Maximum torque $(\mathrm{Nm})$ & 4.5 & 6.5 & 5.0 \\
Minimum torque $(\mathrm{Nm})$ & 2.7 & -2.7 & 2.3 \\
Torque ripple $(\%)$ & 24.5 & 242.1 & 37.0 \\
\hline
\end{tabular}

Table 3. Composition of harmonics.

\begin{tabular}{ccc}
\hline Case & Fundamental & Higher Order \\
\hline Method in Ref. [28] & $\sqrt{ }$ & $\sqrt{ }$ \\
Method in Ref. [29] & $\sqrt{ }$ & $\sqrt{ }$ \\
Proposed method & $\sqrt{ }$ & $\times$ \\
\hline
\end{tabular}

\subsection{Experiment}

In order to validate the effectiveness of the theoretical analysis, a five-phase FT-PMV machine was designed and built. For this experiment, a digital signal processing TMS320F2812 is used to implement the control. A separately excited dc generator is used as the variable load. To measure the torque of the proposed machine drive, a transient torque transducer is mounted between the five-phase FT-PMV machine and the dc generator. Moreover, the currents are sensed by the Hall-effect sensors and the position signal is obtained by the optical encoder with an accuracy of 2048 counts per revolution. Experimental setup of the five-phase FT-PMV machine is presented in Figure 7. 

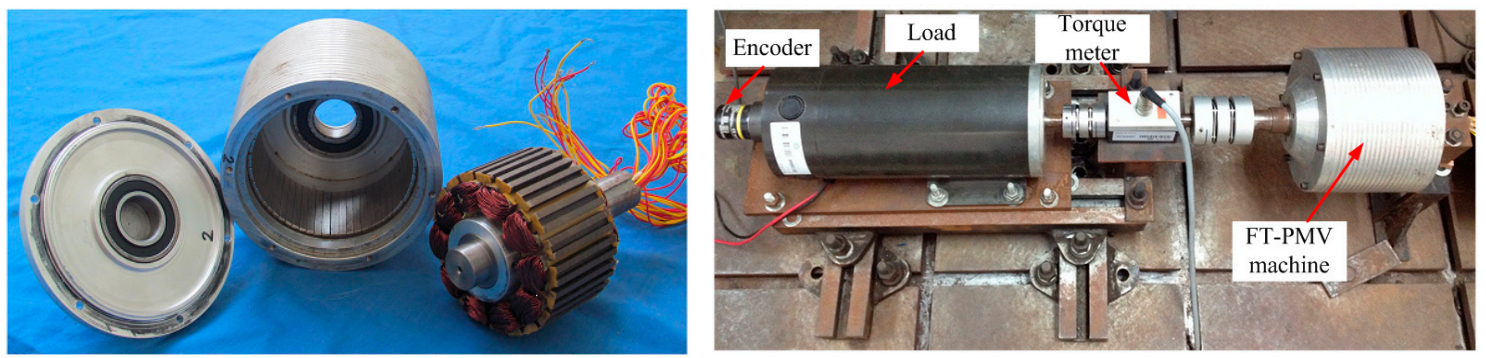

Figure 7. Experimental setup.

The block diagram of the fault-tolerant control scheme is illustrated in Figure 8, in which $\omega_{\text {ref }}$ is the reference speed, $\xi$ is the position angle feedback from the machine. The currents $i_{b}{ }_{b}, i^{*}{ }_{c}, i_{d}{ }_{d}$ and $i_{e}{ }_{e}$ of the short-circuit fault-tolerant control strategy are calculated by using (23). The signals in the gate driver for a five-phase inverter come from a hysteresis current controller.

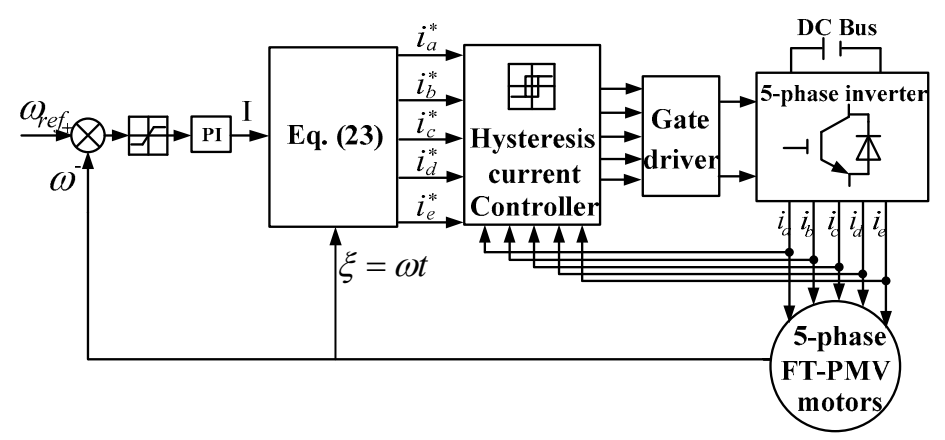

Figure 8. Block diagram of proposed fault-tolerant control scheme.

Moreover, the short-circuit current of the fault phase and the back-EMFs of other healthy phases are shown in Figure 9, verifying the fault-tolerant capability of the FT-PMV machine.

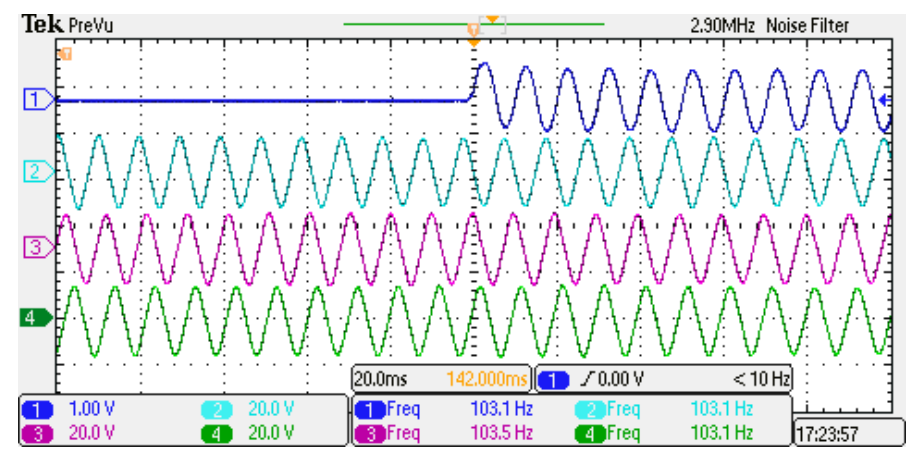

Figure 9. Measured short-circuit phase current (trace 1) and its adjacent phase back-EMFs (traces 2-4) (10 ms/div, $10 \mathrm{~A} /$ div, $20 \mathrm{~V} /$ div).

Furthermore, Figure 10a shows the output torque and the currents of the FT-PMV machine under healthy conditions, while those under the fault-tolerant condition are shown in Figure 10b (the second trace is the current of the short-circuit fault phase). By comparing the measured torque and current waveforms at normal and fault-tolerant operations, it can be concluded that the proposed fault-tolerant control strategy can maintain the torque capability and minimize the torque ripple under the short-circuit fault condition. 


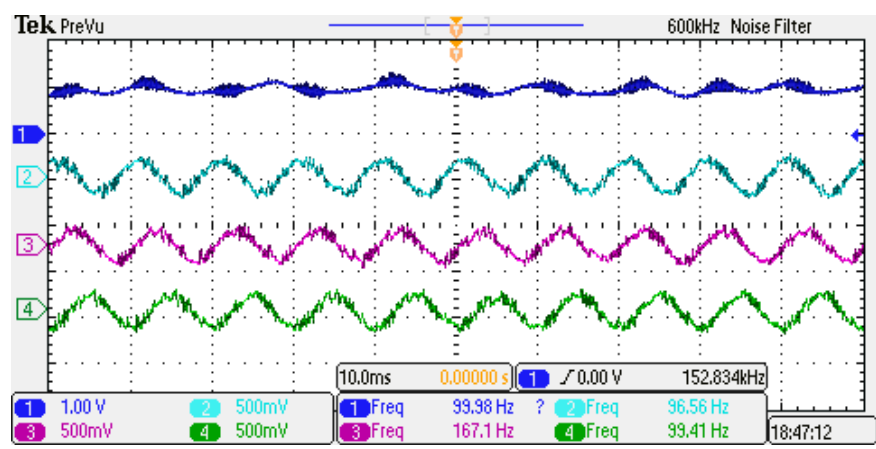

(a)

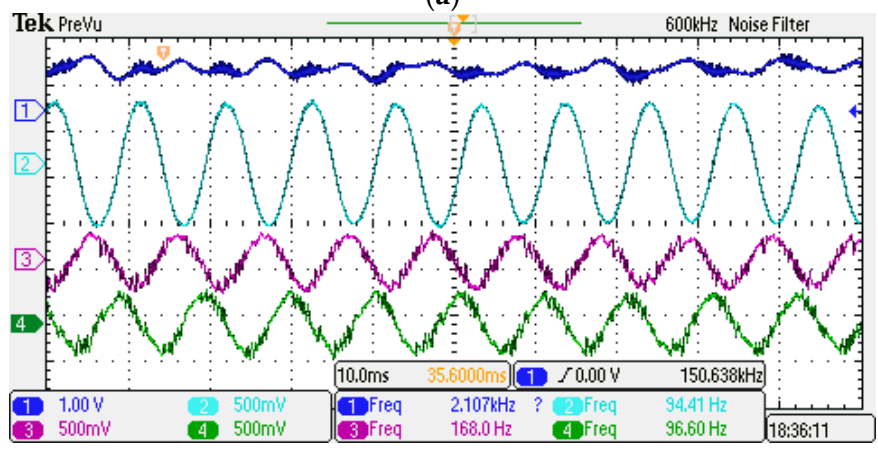

(b)

Figure 10. Measured torque (trace 1) and currents (traces 2-4). (10 ms/div, $2 \mathrm{Nm} / \mathrm{div}, 5 \mathrm{~A} / \mathrm{div}$ ): (a) Normal condition; (b) Fault-tolerant condition.

Figure 11 shows the dynamic responses of the speed and current under sudden changes in load torque when the machine operates in the fault-tolerant mode. It can be seen that the speed regulation is very good.

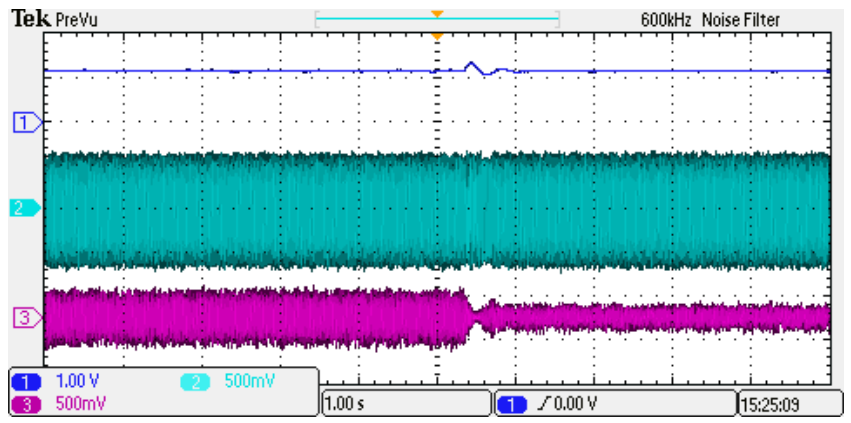

(a)

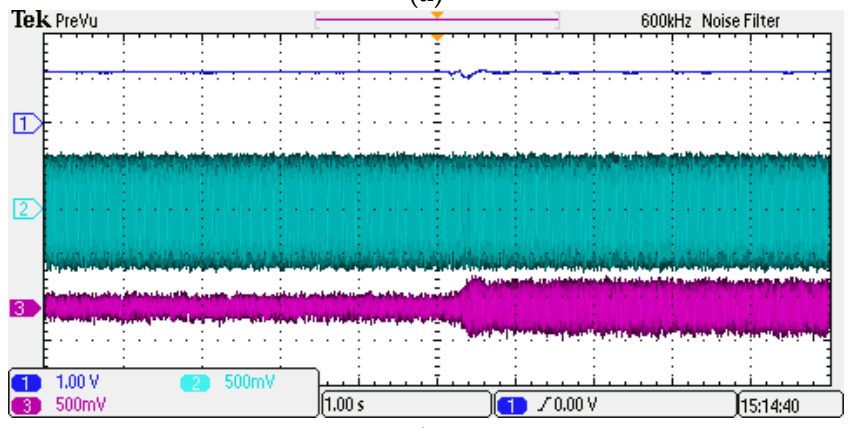

(b)

Figure 11. Measured speed (trace 1), short-circuit current (trace 2) and normal current (lower trace 3) responses at a sudden change of load under fault-tolerant condition $(1 \mathrm{~s} / \mathrm{div}, 160 \mathrm{rpm} / \mathrm{div}, 5 \mathrm{~A} / \mathrm{div})$ : (a) Load decrease; (b) Load increase. 


\section{Comparisons and Discussion}

Compared to these existing methods, the proposed method has obvious difference. First, the expression of the proposed remedial currents is simpler than these previous methods. In fact, the calculation methods in [28,29] are similar to that in [27]. Also, the fault in [31] occurs in the inverter, which is different from the fault discussed in the paper. So, in this section, only the method proposed in [27] is compared as an example.

Applying the method in [27] to the proposed sine back-EMF machine, the final expression can be derived as

$$
\left[\begin{array}{l}
i_{a} \\
i_{b} \\
i_{c} \\
i_{d} \\
i_{e}
\end{array}\right]=\left[\begin{array}{l}
-i_{f} \\
\frac{2.5 I-8.4 \cos (w t) \cos (w t-1.42 \pi)}{10-5 \cos (w t)}\left[4 \cos \left(w t-\frac{2}{5} \pi\right)+\cos (w t)\right] \\
\frac{2.5 I-8.4 \cos (w t) \cos (w t-1.42 \pi)}{10-5 \cos 2(w t)}\left[4 \cos \left(w t-\frac{4}{5} \pi\right)+\cos (w t)\right] \\
\frac{2.5 I-8.4 \cos (w t) \cos (w t-1.42 \pi)}{10-5 \cos ^{2}(w t)}\left[4 \cos \left(w t+\frac{4}{5} \pi\right)+\cos (w t)\right] \\
\frac{2.5 I-8.4 \cos (w t) \cos ^{2}(w t-1.42 \pi)}{10-5 \cos ^{2}(w t)}\left[4 \cos \left(w t+\frac{2}{5} \pi\right)+\cos (w t)\right]
\end{array}\right]
$$

Its waveform plots are shown as Figure 12. The FFT of the currents is shown as Figure 13. Figure 14 shows the torque under fault-tolerant condition. The corresponding average torque and torque ripple factor of the machine drive are $3.6 \mathrm{Nm}$ and $44.8 \%$, respectively. It is obvious that both the proposed method and the method in [27] can maintain the torque performance, whereas the method in [27] leads to higher order harmonics. In addition, for a sinusoidal back-EMF machine, the lower harmonic in currents offers some important advantages. For instance, based on the principle of instantaneous electrical input power and mechanical output balance condition, the reactive component in instantaneous power produced by pulsating torque can be reduced by eliminating higher harmonics in the currents. At the same time, it can reduce iron loss.

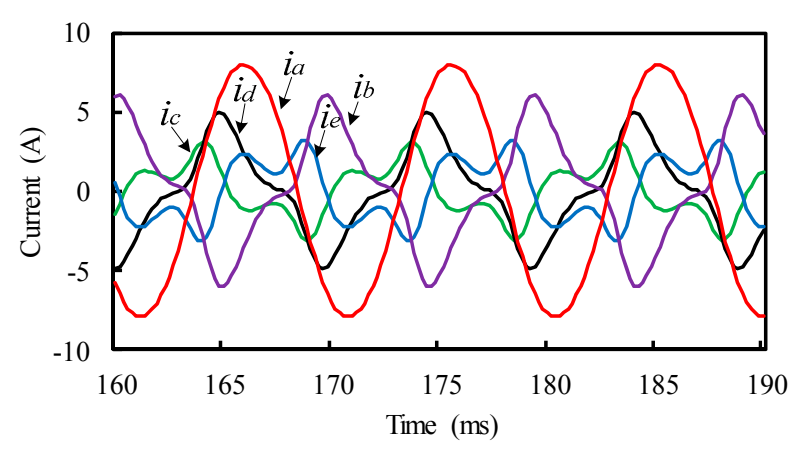

Figure 12. Currents under fault-tolerant conditions.

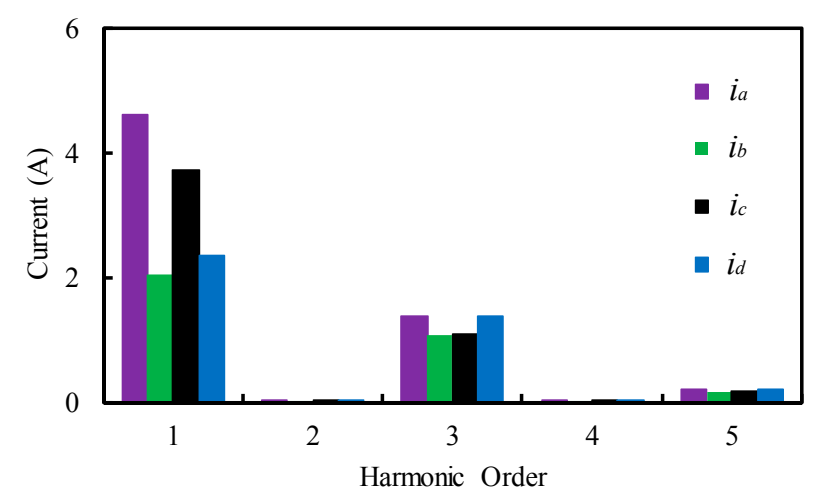

Figure 13. FFT of the currents. 


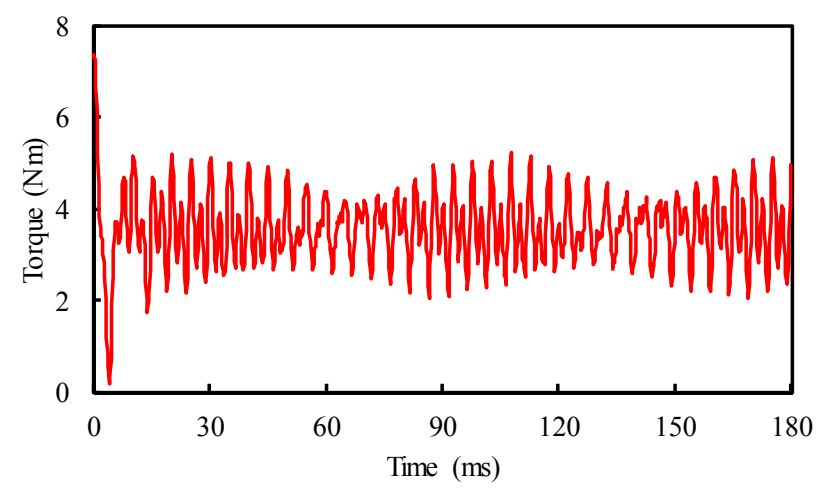

Figure 14. Torque under fault-tolerant conditions.

\section{Conclusions}

In this paper, a remedial current control strategy for a five-phase FT-PMV machine under short-circuit fault conditions has been proposed, which is based on the cooper loss minimization theory. The remedial currents have been calculated to minimize output torque ripple and machine copper losses. A five-phase FT-PMV machine has been built to verify the proposed current control strategy. It exhibits good torque performance when operating under fault-tolerant conditions. The proposed control strategy has been validated by the simulation and experimental results. The simulation and the experiment show that the proposed control strategy can reduce copper losses, maintain torque performance and minimize torque ripple during a short-circuit fault. Hence, it has a bright future in high-reliability and high torque density applications.

Acknowledgments: This work was supported by the National Natural Science Foundation of China (Project 51422702), by the Qing Lan Project of Jiangsu Province, and by the Priority Academic Program Development of Jiangsu Higher Education Institutions.

Author Contributions: Chenyu Gu and Wenxiang Zhao proposed the remedial control strategy; Chenyu Gu and Bufeng Zhang performed the simulations and the experiments.

Conflicts of Interest: The authors declare no conflict of interest.

\section{References}

1. Cheng, M.; Sun, L.; Buja, G.; Song, L. Advanced electrical machines and machine-based systems for electric and hybrid vehicles. Energies 2015, 8, 9541-9564. [CrossRef]

2. Jiang, X.; Huang, W.; Cao, R.; Hao, Z.; Li, J. Analysis of a dual-winding fault-tolerant permanent magnet machine drive for aerospace applications. IEEE Trans. Magn. 2015, 51, 8114704. [CrossRef]

3. Zhao, J.; Gao, X.; Li, B.; Liu, X.; Guan, X. Open-phase fault tolerance techniques of five-phase dual-rotor permanent magnet synchronous motor. Energies 2015, 8, 12810-12838. [CrossRef]

4. Bianchi, N.; Bolognani, S.; Zigliotto, M.; Zordan, M. Innovative remedial strategies for inverter faults in IPM synchronous motor drives. IEEE Trans. Energy Convers. 2003, 18, 306-314. [CrossRef]

5. Mendes, A.M.S.; Cardoso, A.J.M. Fault-tolerant operating strategies applied to three-phase induction-motor drives. IEEE Trans. Ind. Electron. 2006, 53, 1807-1817. [CrossRef]

6. Ding, W.; Hu, Y.; $\mathrm{Wu}, \mathrm{L}$. Investigation and experimental test of fault-tolerant operation of a mutually coupled dual three-phase SRM drive under faulty conditions. IEEE Trans. Power Electron. 2015, 30, 6857-6872. [CrossRef]

7. Wang, Z.; Chen, J.; Cheng, M.; Zheng, Y. Fault tolerant control of paralleled voltage-source inverters fed PMSM drives. IEEE Trans. Ind. Electron. 2015, 62, 4749-4760. [CrossRef]

8. Levi, E.; Bojoi, R.; Profumo, F.; Toliyat, H.; Williamson, S. Multiphase induction motor drives-A technology status review. IET Electr. Power Appl. 2007, 1, 489-516. [CrossRef]

9. Baek, S.K.; Shin, H.U.; Kang, S.Y.; Park, C.S.; Lee, K.B. Open fault detection and tolerant control for a five phase inverter driving system. Energies 2016, 9, 355. [CrossRef] 
10. Wang, D.; Liu, C.; Li, G. An optimal integrated control scheme for permanent magnet synchronous generator-based wind turbines under asymmetrical grid fault conditions. Energies 2016, 9, 307. [CrossRef]

11. Duran, M.J.; Barrero, F. Recent advances in the design, modeling, and control of multiphase machines. IEEE Trans. Ind. Electron. 2016, 63, 459-468. [CrossRef]

12. Mohammadpour, A.; Parsa, L. A unified fault-tolerant current control approach for five-phase PM motors with trapezoidal back EMF under different stator winding connections. IEEE Trans. Power Electron. 2013, 28, 3517-3527. [CrossRef]

13. Prieto, B.; Martínez-Iturralde, M.; Fontán, L.; Elosegui, I. Fault-tolerant permanent magnet synchronous machine-phase, pole and slot number selection criterion based on inductance calculation. IET Electr. Power Appl. 2015, 9, 138-145. [CrossRef]

14. Liu, G.; Qu, L.; Zhao, W.; Chen, Q.; Xie, Y. Comparison of two SVPWM control strategies for give-phase fault-tolerant permanent-magnet motor. IEEE Trans. Power Electron. 2016, 31, 6621-6630. [CrossRef]

15. Zhao, W.; Cheng, M.; Hua, W.; Jia, H.; Cao, R. Back-EMF harmonic analysis and fault-tolerant control of flux-switching permanent-magnet machine with redundancy. IEEE Trans. Ind. Electron. 2011, 58, 1926-1935. [CrossRef]

16. Chen, Q.; Liu, G.; Zhao, W.; Sun, L.; Shao, M.; Liu, Z. Design and comparison of two fault-tolerant interior-permanent-magnet motors. IEEE Trans. Ind. Electron. 2014, 61, 6615-6623. [CrossRef]

17. Liu, G.; Yang, J.; Zhao, W.; Ji, J.; Chen, Q.; Gong, W. Design and analysis of a new fault-tolerant permanent-magnet vernier machine for electric vehicles. IEEE Trans. Magn. 2012, 48, 4176-4179. [CrossRef]

18. Dwari, S.; Parsa, L. An optimal control technique for multiphase PM machines under open-circuit faults. IEEE Trans. Ind. Electron. 2008, 55, 1988-1995. [CrossRef]

19. Dwari, S.; Parsa, L. Fault-tolerant control of five-phase permanent-magnet motors with trapezoidal back EMF. IEEE Trans. Ind. Electron. 2011, 58, 476-485. [CrossRef]

20. Tani, A.; Mengoni, M.; Zarri, L.; Serra, G.; Casadei, D. Control of multiphase induction motors with an odd number of phases under open-circuit phase faults. IEEE Trans. Power Electron. 2012, 27, 565-577. [CrossRef]

21. Kestelyn, X.; Semail, E. A vectorial approach for generation of optimal current references for multiphase permanent magnet synchronous machines in real time. IEEE Trans. Ind. Electron. 2011, 58, 5057-5065. [CrossRef]

22. Zhao, W.; Cheng, M.; Chau, K.T.; Cao, R.; Ji, J. Remedial injected-harmonic-current operation of redundant flux-switching permanent-magnet motor drives. IEEE Trans. Ind. Electron. 2013, 60, 151-159. [CrossRef]

23. Mohammadpour, A.; Sadeghi, S.; Parsa, L. A generalized fault-tolerant control strategy for five-phase PM motor drives considering star, pentagon, and pentacle connections of stator windings. IEEE Trans. Ind. Electron. 2014, 61, 63-75. [CrossRef]

24. Salehifar, M.; Salehi Arashloo, R.; Moreno-Eguilaz, M.; Sala, V.; Romeral, L. Observer-based open transistor fault diagnosis and fault-tolerant control of five-phase permanent magnet motor drive for application in electric vehicles. IET Power Electron. 2015, 8, 76-87. [CrossRef]

25. Bianchi, N.; Bolognani, S.; Pre, M. Strategies for the fault-tolerant current control of a five-phase permanent-magnet motor. IEEE Trans. Ind. Appl. 2007, 43, 960-970. [CrossRef]

26. Mohammadpour, A.; Mishra, S.; Parsa, L. Fault-tolerant operation of multiphase permanent-magnet machines using iterative learning control. IEEE J. Emerg. Sel. Top. Power Electron. 2014, 2, 201-211. [CrossRef]

27. Mohammadpour, A.; Parsa, L. Post-fault control technique for multi-phase PM motor drives under short-circuit faults. In Proceedings of the 2013 Twenty-Eighth Annual IEEE Applied Power Electronics Conference and Exposition (APEC), Long Beach, CA, USA, 17-21 March 2013.

28. Mohammadpour, A.; Parsa, L. Global fault-tolerant control technique for multi-phase permanent-magnet machines. IEEE Trans. Ind. Appl. 2015, 51, 178-186. [CrossRef]

29. Sen, B.; Wang, J. Stationary frame fault-tolerant current control of polyphase permanent-magnet machines under open-circuit and short-circuit faults. IEEE Trans. Power Electron. 2016, 31, 4684-4696.

30. Sedrine, E.B.; Ojeda, J.; Gabsi, M.; Slama-Belkhodja, I. Fault-tolerant control using the GA optimization considering the reluctance torque of a five-phase flux switching machine. IEEE Trans. Energy Convers. 2015, 30, 927-938. [CrossRef]

31. Nguyen, N.; Meinguet, F.; Semail, E.; Kestelyn, X. Fault-tolerant operation of an open-end winding five-phase PMSM drive with short-circuit inverter fault. IEEE Trans. Ind. Electron. 2016, 63, 595-605. [CrossRef] 
32. Jen-Ren, F.; Lipo, T.A. Disturbance-free operation of a multiphase current-regulated motor drive with an opened phase. IEEE Trans. Ind. Appl. 1994, 30, 1267-1274. [CrossRef]

33. Atallah, K.; Wang, J.; Howe, D. Torque-ripple minimization in modular permanent-magnet brushless machines. IEEE Trans. Ind. Appl. 2003, 39, 1689-1695. [CrossRef]

(c) 2016 by the authors; licensee MDPI, Basel, Switzerland. This article is an open access article distributed under the terms and conditions of the Creative Commons Attribution (CC-BY) license (http://creativecommons.org/licenses/by/4.0/). 